\title{
Biochemical effects of nandrolone decanoate abuse on experimental animal model
}

\author{
Neveen A Salem ${ }^{1,2 *}$ and Hanan S Alnahdi ${ }^{1}$ \\ ${ }^{1}$ Department of Biochemistry, Faculty of Science, University of Jeddah, Saudi Arabia \\ ${ }^{2}$ Narcotics, Ergogenic Aids and Poisons Department, Medical Research Division, National Research Centre, Giza, Egypt
}

\begin{abstract}
Rational: Nandrolone decanoate (ND) is one of the most commonly abused anabolic androgenic steroids compound in the world in order to improve physical performance but its abuse is associated with several adverse effects.

Objectives: The current study was performed to evaluate the effect of recommended and overdose of nandrolone decanoate for short and long term on the alterations of biochemical markers related to kidney, liver, adrenal, thyroid gland functions and the levels of oxidant and antioxidant activities.

Methods: Sixty adult male albino rats were randomly assigned into two major groups. The first was treated with ND for 6 weeks and the second was treated with same drug for 12 weeks. Each of these groups were further subdivided into three subgroups: 1-Control (untreated rats), 2 - Rats intraperitoneally injected with 3 mg/ $\mathrm{kg}$. weekly, 3- Rats intraperitoneally injected with $15 \mathrm{mg} / \mathrm{kg}$ weekly.

Results: Ingesting male rats with high ND dose for either short or long term significantly elevated kidney function biomarkers (serum creatinine, urea, uric acid and NAG), liver function biomarkers (serum AST, ALT, cytosolic AST,ALT and mitochondrial AST), slightly increased thyroid function (T3 ant T4) and insignificantly attenuated TSH. It significantly increased adrenal function (corticosterone) while, decreased ACTH. Moreover, oxidative stress biomarkers (superoxide anion and lipid peroxides) were significantly upregulated associated with depression in superoxide dismutase and catalase activities.
\end{abstract}

Conclusion: The use of high ND dose for either short or long term as well as the repeated use of recommended ND dose for long term proved to have harmful effects manifested in impairing the functions of kidneys, liver, thyroid, adrenal glands as well as oxidant antioxidant balance.

\section{Introduction}

Nandrolone decanoate (ND) is one of the most commonly abused anabolic androgenic steroids (AAS) compound in the world due to its androgenic potential associated with the favored anabolic properties [1]. The use of ND has been applied for therapeutic purposes and has proven to be effective in reducing loss of body mass and muscle in human immune efficiency virus (HIV) patients [2], increasing the number of satellite cells per muscle fiber [3], and controlling refractory anemia [4]. It is also used in the treatment of hypogonadism, bone marrow failure syndromes, bone mineralization and some muscle wasting disorders [5].

The recommended therapeutic dose of ND for human is $0.4 \mathrm{mg} /$ $\mathrm{kg} /$ day [6]. However, the use of ND has notably increased to improve physical performance and the doses up to 10 to 100 -fold higher than the therapeutic dose are being used and this abuse resulted in several adverse effects [7].

The chronic and unregulated use ND results in undesirable outcomes including oxidative stress [8], renal and hepatic injury [9], coronary problems [10] and psychological disorders [11].

Therefore, the current study was designed to assess the influence of recommended and chronic overdose consumption of ND on the biochemical alterations in reno-hepatic functions, hormonal levels, oxidant and antioxidant biomarkers in male rats.

\section{Materials and methods}

Adult male albino rats weighing $150 \pm 10 \mathrm{~g}$ were used in the present study. The animals were obtained from the animal house colony of National Research Centre. The animals were maintained in wire bottomed cages at room temperature $\left(25 \pm 2^{\circ} \mathrm{C}\right)$ with controlled lightening (12 h light and $12 \mathrm{~h}$ darkness cycle). All animal was accommodated with laboratory conditions for one week before treatment and maintained under the same conditions all over the experimental period. Rodents chow diet and clean water were allowed ad libitum. All animals received human care in compliance with the guidelines of the Ethical Committee of Medical Research of National Research Centre, Egypt. which conform to the recommendations of the National Institutes of Health Guide for Care and Use of Laboratory Animals (Publication No. 85-23, revised1996).

${ }^{\star}$ Correspondence to: Neveen A. Salem, Narcotics, Ergogenic Aids and Poisons Department, Medical Research Division, National Research Centre, Giza, Egypt, Tel: 202 (33335966); Fax: 202 (33370931); E-mail: dr_nsalem@yahoo.com

Key words: nandrolone decanoate, kidney function, liver function, hormonal levels, oxidative stress

Received: May 03, 2019; Accepted: May 17, 2019; Published: May 21, 2019 


\section{Drug and chemicals}

Nandrolone decanoate (Deca-Durabolin) ${ }^{\circ}$ was purchased from Organon Company in the form of ampoule $25 \mathrm{mg}$. all chemicals and reagents used in the experiment were of analytical grade.

\section{Experimental design}

Sixty adult male Wister rats were randomly assigned into two major groups. The first group (group 1) was treated with the ND for short term (6 weeks), while the second group (group II) was treated with the same drug for long term (12 weeks). Each of the short- and long-term groups were subdivided into three subgroups

Subgroup (1): rats were kept without treatment and served as untreated control.

Subgroup (2): rats were intraperitoneally injected with $3 \mathrm{mg} / \mathrm{kg}$ bw ND weekly.

Subgroup (3): rats were intraperitoneally injected with $15 / \mathrm{kg}$ bw ND weekly.

The doses of ND administered to rats and period of administration were similar to that used earlier $[12,13]$ and mimics one cycle of AAS abuse by athletes.

\section{Sampling}

At the end of treatment period, animals were fasted overnight and then anaesthetized using urethane $(1.4 \mathrm{ml} / \mathrm{kg})$.

\section{Blood sampling}

Blood samples were collected from the retro-orbital venous plexus. One portion of each blood sample was collected in dry centrifuge tubes and left to clot and then centrifuged at $3000 \mathrm{xg}$ for 15 minutes at $4^{\circ} \mathrm{C}$ as aliquots for further determination of creatinine, urea uric acid, Acetyl $\beta$-glucosaminidase (NAG), Aspartate amino transferase (AST), alanine amino transferase (ALT), triiodothy-ronine $\left(\mathrm{T}_{3}\right)$, tyroxine $\left(\mathrm{T}_{4}\right)$ and thyroid stimulating hormone (TSH). The other portion of each blood sample was collected in heparinized tubes and then centrifuged at 3000 $\mathrm{xg}$ for 20 minutes at $4^{\circ} \mathrm{C}$ for separation of plasma. Plasma samples were stored at $-20^{\circ} \mathrm{C}$ for corticosterone and adrenocorticotrophic hormone (ACTH) determinations.

\section{Tissue sampling}

After blood collection, all animals were rapidly sacrificed and the right kidney and liver of each animal was removed by dissection, washed from blood by ice-cold isotonic saline and blotted between two filter papers, then part of each harvested kidney and liver was shock frozen in liquid nitrogen $\left(-170^{\circ} \mathrm{C}\right)$ and stored at $-20^{\circ} \mathrm{C}$ for further determination of superoxide anion $\left(\mathrm{O}_{2}\right)$, malondialdehyde (MDA), superoxide dismutase (SOD) and catalase (CAT) in kidney tissues and cytosolic ALT, AST and mitochondrial AST in liver tissues.

\section{Biochemical analysis}

Serum creatinine was measured as described by Henry [14] using diamond diagnostics kits (Egypt), following the instructions of manufacturer. Serum urea was quantitatively determined using QCA kit (Quimica Clinica Apilicada SA) with the modified Searcy et al. [15] method. Serum uric acid concentration was determined colorimetrically as described by Haisman et al. [16] using stabio uric acid liquicolor kit (USA). Serum N-acetyl- $\beta$ glocosamindase (NAG) was determined colorimetrically as described by Luqmani et al. [17] using diagnostics FAR kit (Italy).
The activities of serum AST and ALT were determined using kits provided by stanbio Laboratory (USA) according to Reitman et al. [18].

Serum triiodthyronine $\left(\mathrm{T}_{3}\right)$ and thyroxine $\left(\mathrm{T}_{4}\right)$ concentrations were determined according to Walker [19] and Schuurs et al. [20], respectively by enzyme immune assay (EIA) kits (Cal. Tech. Diagnostics INCaaa (USA). Serum thyroid stimulating hormone (TSH) was determined according to Morimoto et al. [21] by solid phase enzyme linked immune assay (ELISA) kits (Immuno Biological Laboratories, Inc (IBL. Germany).

Plasma corticosterone was determined according to Krame et al. [22] by Enzyme Immuno Assay kits (IBL Immuno Biological Laboratories Germany). Plasma adrenocorticotrophic hormone (ACTH) was determined as described by Odell et al. [23] using solid phase enzyme linked immune sorbent assay kit (Biomerica Inc. USA).

The stored kidneys were homogenized in Teflon-glass homogenizer with buffer containing $1.5 \%$ potassium chloride to obtain 1:10 (w/v) of whole homogenate to determine oxidant biomarkers and antioxidant enzyme activities in renal tissue. The homogenate was prepared for analysis by centrifugation at $18,000 \times \mathrm{g}\left(4^{\circ} \mathrm{C}\right)$ for $30 \mathrm{~min}$.

Renal tissue superoxide anion was determined according to the modified method of Hassoun et al. [24] following the principle of Babior et al. [25] which measured the production of superoxide anion in tissue on the basis of cytochrome $c$ reduction. Lipid peroxidation was determined according to Placer et al. [26] which depends on the determination of thiobarbituric acid reactive substance (TBARS) content.

Total protein in tissue homogenate was determined according to Chromy et al. [27] using diagnostic kits provided by Biocon (Germany) following the instructions of manufacturer.

The activity of tissue superoxide dismutase (SOD) was measured using the method of Marklund [28]. Tissue catalase activity was determined according to Clairborne method [29].

The stored livers were homogenized using potter glass homogenizer for two minutes. The respective homogenate was centrifuged at 25000 $\mathrm{xg}$ in Sorvall Dupont (USA) ultracentrifuge for two hours at $4^{\circ} \mathrm{C}$. Liver cytosol was prepared according to the method of Yeung et al. [30]. Determination of cytosolic AST and ALT was the same as that of serum AST and ALT using $0.2 \mathrm{ml}$ liver cytosol instead of serum. Liver mitochondria was separated according to the method of Hogeboom [31]. The pure mitochondria was resuspended in $5 \mathrm{ml}$ of $0.25 \mathrm{~mol} / \mathrm{L}$ sucrose and kept over-night after the addition of $0.06 \%$ wv Triton X 100 in order to release the enzyme from mitochondria [32]. Determination of mitochondrial AST was the same as that of serum AST using $0.2 \mathrm{ml}$ of liver mitochondrial fraction instead of serum.

\section{Statistical analysis}

The obtained data were statistically analyzed. The values are expressed as mean $\pm \mathrm{SD}$. The differences between groups were assessed by one-way analysis of variance (ANOVA), using SPSS software (IBM, New York USA). Intergroup comparisons were performed by Duncan's multiple rank test using MSTAT-C computer program. Mean values followed by the same alphabetical letter are not significantly different. Differences were significant at $p<0.05$. 


\section{Results}

\section{Renal function}

\section{Creatinine concentration}

Creatinine level in serum is typically used to monitor kidney function. In the present study ingesting male rats with high ND dose (15 mg/kg/week) for either short-term (6 week) or long-term (12 weeks) significantly elevated the level of serum creatinine However the recommended ND dose ( $3 \mathrm{mg} / \mathrm{kg} /$ week) for short term had no significant effect on serum creatinine. Whereas the low dose (recommended dose) of ND for long term resulted in significant increment in the level of serum creatinine (Figure 1A).

\section{Urea concentration}

Urea is the principal nitrogenous waste product of protein breakdown. It is eliminated from the body almost exclusively by the kidneys in urine. The measurement of urea concentration in blood has had clinical application in the assessment of renal function.

Ingesting male rats with the supraphysiological ND dose $(15 \mathrm{mg} /$ $\mathrm{kg} /$ week) for either short term (6 week) or long term (12 weeks) significantly elevated the level of serum urea by $59 \%$ and $81 \%$, respectively as compared to the control. However, ingesting male rats with $3 \mathrm{mg} \mathrm{ND} / \mathrm{kg} /$ week for either short or long term had no significant effects on serum urea (Figure 1B).

\section{Uric acid concentration}

An increase in uric acid level may be a consequence of increased cell breakdown associated with renal disease. As show in ingesting male rats with high ND dose ( $15 \mathrm{mg} / \mathrm{kg} /$ week) for either short or long term induced significant increments in serum uric acid level by $47 \%$ and $113 \%$ as compared to the untreated rats. However, the low ND dose (3 $\mathrm{mg} / \mathrm{kg} /$ week) for short term (6 weeks) had no significant effects on the level of serum uric acid. In contrast, the low ND dose (3 mg/ $\mathrm{kg} /$ weed) for long term (12 weeks) resulted in significant elevation of serum uric acid by $8 \%$ as compared to the control (Figure 1C).

\section{4-Serum $N$-acetyl $\beta$-glucosaminidase (NAG)}

Serum NAG is considered to be a sensitive indicator of renal tubular impairment. It is associated with the lysosomal membrane, so it would not be lost into the urine unless the tubular cells were damaged Ingesting male rats with the high ND dose ( $15 \mathrm{mg} / \mathrm{kg} /$ week) for either short or long term resulted in significant elevation in serum NAG by $141 \%$ and $218 \%$ respectively in comparison with the untreated rats.

On the other hand, the low ND dose ( $3 \mathrm{mg} / \mathrm{kg} /$ week) for short term had no significant effects on serum NAG. However, ingesting male rats with low ND dose ( $3 \mathrm{mg} / \mathrm{kg} /$ week) for long term (12 weeks) resulted in significant elevation in the level of serum NAG by $41 \%$ as compared to the control (Figure 1D).

\section{Liver function}

\section{Serum AST and ALT activities}

Aspartate aminotransferase (AST) and alanine aminotransferase (ALT) are two of the most reliable markers of hepatocellular injury or necrosis. ingesting male rats with the Supra physiological ND dose (15 mg/kg/week) for either short or long term significantly increased both AST and ALT by $35 \%, 52 \%, 64 \%$ and $85 \%$ in the same respect in comparison with the untreated rats. However, administration of the low ND dose ( $3 \mathrm{mg} / \mathrm{kg} /$ week) for 6 weeks had no significant effect on both serum AST and ALT. Ingesting male rats with the low dose for 12 weeks resulted in significant increment of $21 \%$ for AST and $18 \%$ for ALT as compared to the untreated rats (Figure $2 \mathrm{~A}$ and $2 \mathrm{~B}$ ).

\section{Liver cytosolic AST and ALT}

Supra physiological ND dose administration (15 mg/kg/week) for either short or long term induced significant elevations in both cytosolic AST and ALT activities by 75\%, 140\%, 77\% and 164\% with the same respect in comparison with the untreated rats. The low ND dose (3 $\mathrm{mg} / \mathrm{kg} /$ week) for either short or long term did not affect significantly the activity of cytosolic AST in liver tissues. In addition, it had no significant effect in the case of short term for cytosolic ALT. however in the case of long term it induced significant elevation by $37 \%$ for cytosolic ALT activity as compared to the untreated rats (Figure $2 \mathrm{C}$ and 2S).

\section{Mitochondrial AST activity}

The results revealed that ingesting male rats with the high ND dose (15 mg/kg/week) for either short or long term resulted in significant increases in mitochondrial AST by $49 \%$ and $186 \%$ respectively as compared to the control. However, administration of the low ND dose ( $3 \mathrm{mg} / \mathrm{kg} /$ week) for either short or long term had no significant effect on mitochondrial AST activity (Figure 2E).

\section{Hormonal levels}

\section{Serum $T_{3}, T_{4}$ and TSH levels}

Considering the effect of ND on serum $\mathrm{T}_{3}, \mathrm{~T}_{4}$ and TSH levels, the results showed that ingesting male rats with either recommended dose ( $3 \mathrm{mg} / \mathrm{kg} /$ week) or overdose $(15 \mathrm{mg} / \mathrm{kg} /$ week) of ND for both short or long term had no significant effect on $\mathrm{T}_{3}, \mathrm{~T}_{4}$ and TSH levels. as compared to the normal control. However, the mean values of $\mathrm{T}_{3}$ and $\mathrm{T}_{4}$ tended to increase by administration with low and high ND dose, while the mean values of TSH level tended to decrease (Figure 3A-3C).

\section{Plasma corticosterone concentration}

Current data showed that the low dose of ND for short term did not affect significantly the concentration of corticosterone. However, the low dose for long term induced significant elevation of $26 \%$ as compared to the normal control. In addition, ingesting male rats with the ND overdose ( $15 \mathrm{mg} / \mathrm{kg} / \mathrm{week}$ ) for either short or long term resulted in significant elevations of $44 \%$ and $61 \%$ respectively as compared to the normal control (Figure 3D).

\section{Plasma ACTH concentration}

The present results revealed that ingesting male rats with high ND dose (15 mg/kg/week) for either short or long term significantly attenuated the concentrations of plasma ACTH by $-27 \%$ and $-38 \%$, respectively as compared to the normal control. However, the low ND for short term had no significant effect on plasma ACTH concentration. The low ND dose for long term significantly decreased the concentration of plasma ACTH by $-7 \%$ as compared to the untreated rats (Figure 3E).

\section{Oxidant and antioxidant biomarkers}

\section{Superoxide anion $\left(\mathrm{O}_{2}\right)$}

Injecting male rats with high ND dose ( $15 \mathrm{mg} / \mathrm{kg} /$ week) for either short or long term induced significant elevation in the level of superoxide anion by $89 \%$ and $142 \%$, respectively compared to the untreated control rats. The low ND dose (3 mg/kg/week) for short term (6 week) had no significant effect in this respect. However, injecting male rats with 

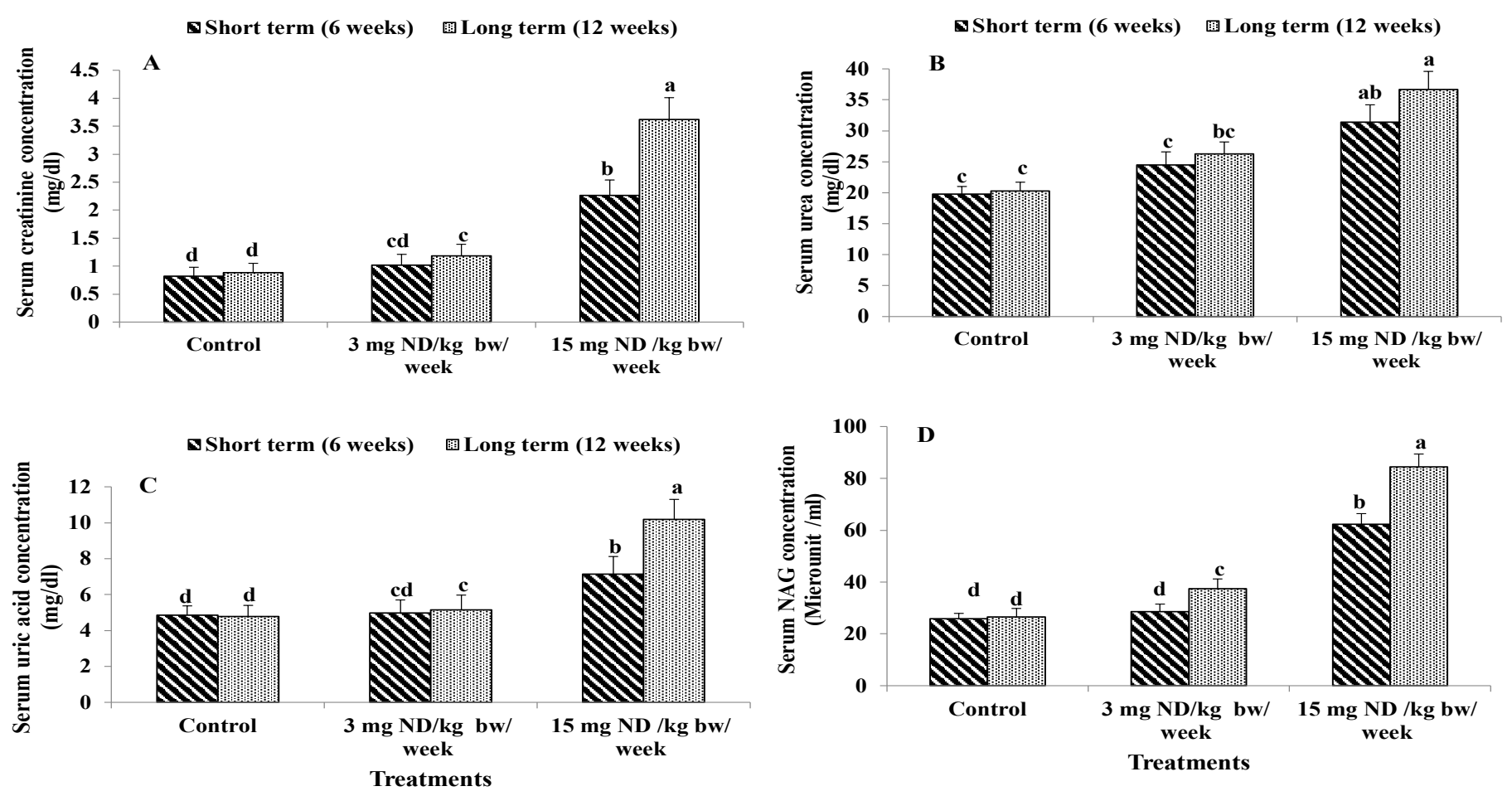

Figure 1. Effect of ND on kidney function: Serum creatinine concentration (A) Serum urea concentration (B) Serum uric acid concentration (C) and Serum NAG concentration (D) Different letters on columns indicate statistically least significant difference (LSD).
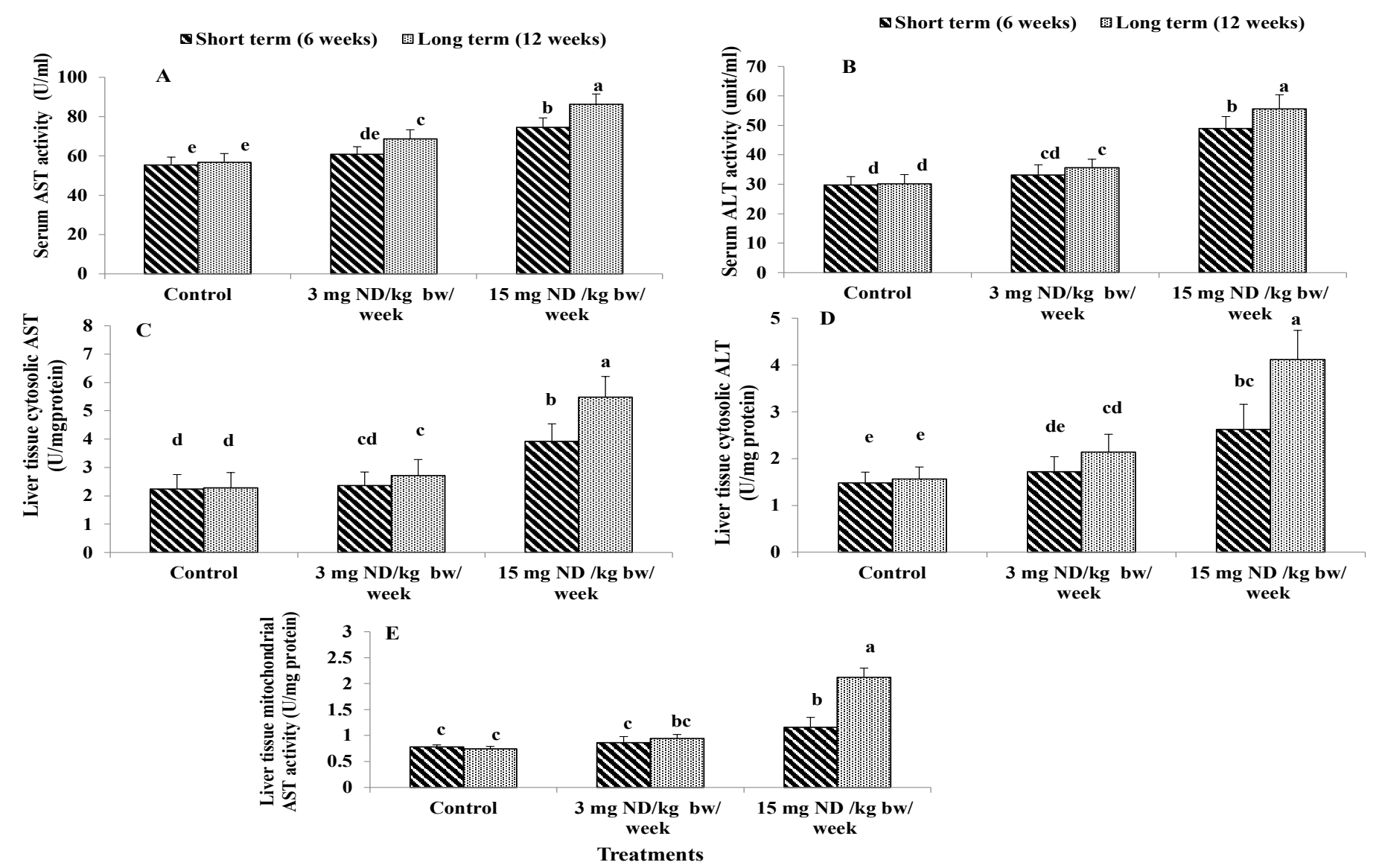

Figure 2. Effect of ND on liver function: serum AST activity (A), Serum ALT activity (B), liver tissue cytosolic AST activity (C) Liver tissue cytosolic ALT activity (D) and Liver tissue mitochondrial AST activity (E) Different letters on columns indicate statistically least significant difference (LSD). 


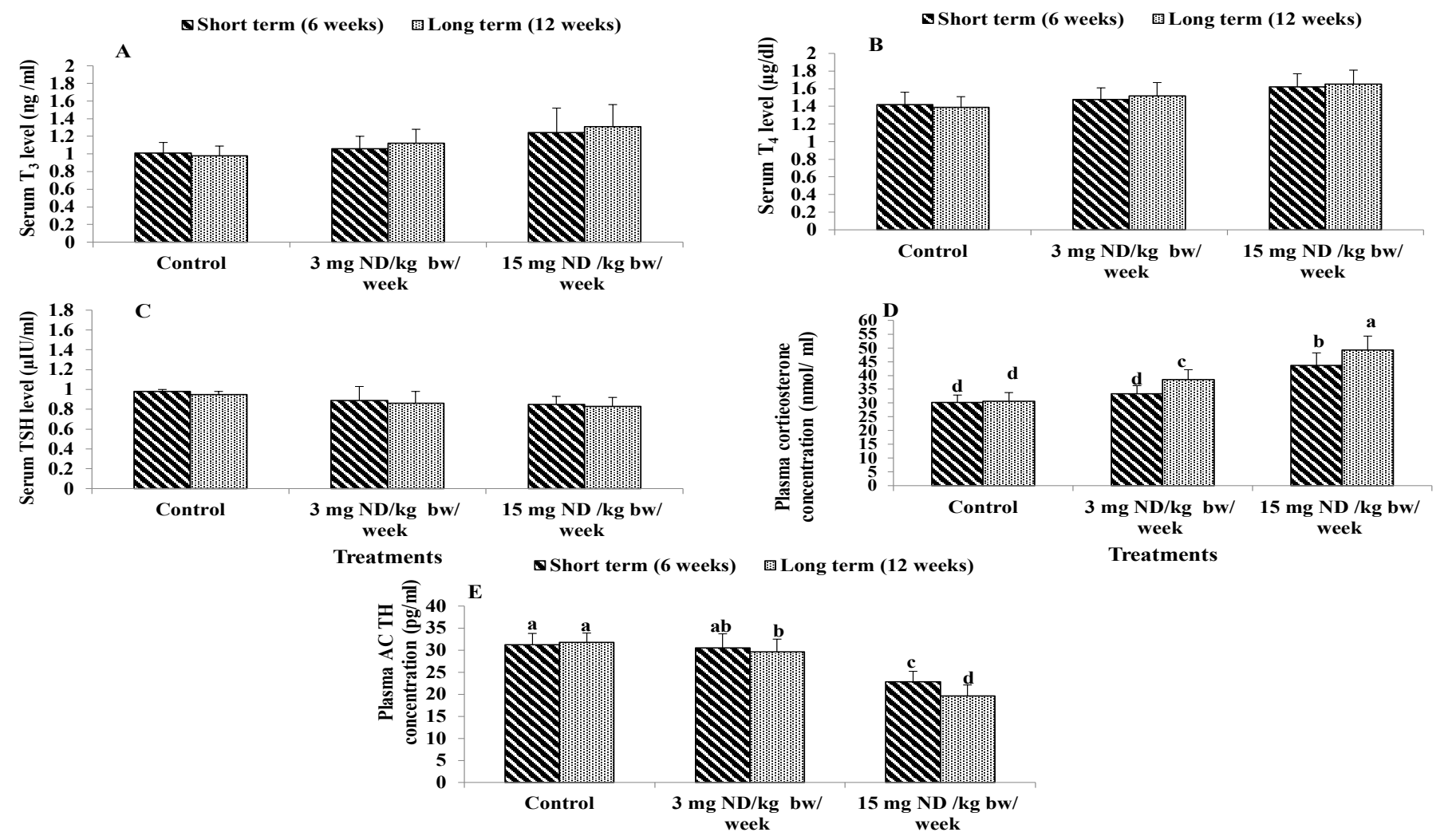

Figure 3. Effect of ND on thyroid and adrenal glands function. Serum T3 level (A) Serum T4 level (B), Serum TSH level (C) Plasma Corticosterone concentration (D) and plasma ACTH concentration (E) . Different letters on columns indicate statistically least significant.

low ND dose for long term (12 week) resulted in significant increase in the level of superoxide anion by $42 \%$ in comparison with the normal control (Figure 4A).

\section{Lipid peroxides}

Data showed that ingesting male rats with high ND dose $(15 \mathrm{mg} /$ $\mathrm{kg} /$ week) for either short or long term significantly elevated the level of lipid peroxidation in tissues by $30 \%$ and $41 \%$ respectively as compared to the normal control. The low ND dose ( $3 \mathrm{mg} / \mathrm{kg} /$ week) for short term (6 week) had no significant effect in this respect. However, the lows ND dose for long term resulted in significant increase in the level of tissue lipid peroxidation by $8 \%$ in comparison with the untreated rats (Figure $4 \mathrm{~B}$ ).

\section{Superoxide dismutase (SOD) activity}

Superoxide dismutase is an enzyme that alternately catalyzes the dismutation of superoxide anion into either ordinary molecular oxygen $\left(\mathrm{O}_{2}\right)$ or hydrogen peroxide $\left(\mathrm{H}_{2} \mathrm{O}_{2}\right)$. The results indicated that ingesting male rats with high ND dose (15 mg/kg/week) for either short or long term caused significant reduction in the activity of SOD in kidney tissues by $-34 \%$ and $-45 \%$, respectively as compared to the normal control .The low ND dose ( $3 \mathrm{mg} / \mathrm{kg} /$ week) for short term had no significant effect in this respect. However, ingesting male rats with low ND dose for long term significantly attenuated the activity of SOD by $11 \%$ as compared to the untreated rats (Figure $4 \mathrm{C}$ ).

\section{Catalase activity}

Rats received high ND dose (15 mg/kg/week) for either short or long term showed significant attenuation in catalase activity by $-20 \%$ and $-39 \%$, respectively as compared to the normal control. The low ND dose for short term had no significant effect on catalase activity.
However, ingesting male rats with the low ND dose for long term significantly attenuated the activity of catalase by $-11 \%$ in comparison with the untreated rats (Figure 4D).

\section{Discussion}

Nandrolone decanoate (ND) is a synthetic anabolic steroid AAS derived from testosterone. It is used for improvement of athletic performance and this drug has been used by weightlifters, elite athletes, bodybuilders and recreational athletes to increase their muscles and decrease fat mass [33]. It becomes one of the most commonly abused AAS in the world [1]. The abuse and chronic use of ND can cause a lot of adverse effects on kidney, liver, hormones, reproductive, cardiovascular, oxidant and antioxidant systems among others [34,35].

The current study aimed to examine the effects of recommended ND dose (3 mg/kg/week) [6] and the high ND dose (15 mg/kg/eek) for either short term ( 6 weeks) and long term (12 weeks) on the alteration of reno-hepatic functions, hormonal levels and oxidative stress biomarkers in male rats.

Ingesting male rats with high ND dose for either short or long term as well as the recommend ND dose for long term led to significant increase in the levels of creatinine, urea, uric acid and NAG. These results are in accordance with the finding of Mohammed et al. [9] who reported high increase of creatinine and urea levels among ND high dose groups, which indicate negative impact of ND on kidney function. Increasing the levels of uric acid may be a consequence of decreased clearance caused by the impairment in glomerular filtration rate (GFR) or it may reflect local tissue hypoxia or increased cell breakdown associated with renal disease [36]. In addition, increasing the levels of NAG is a sensitive indicator of renal tubular impairment [37]. 

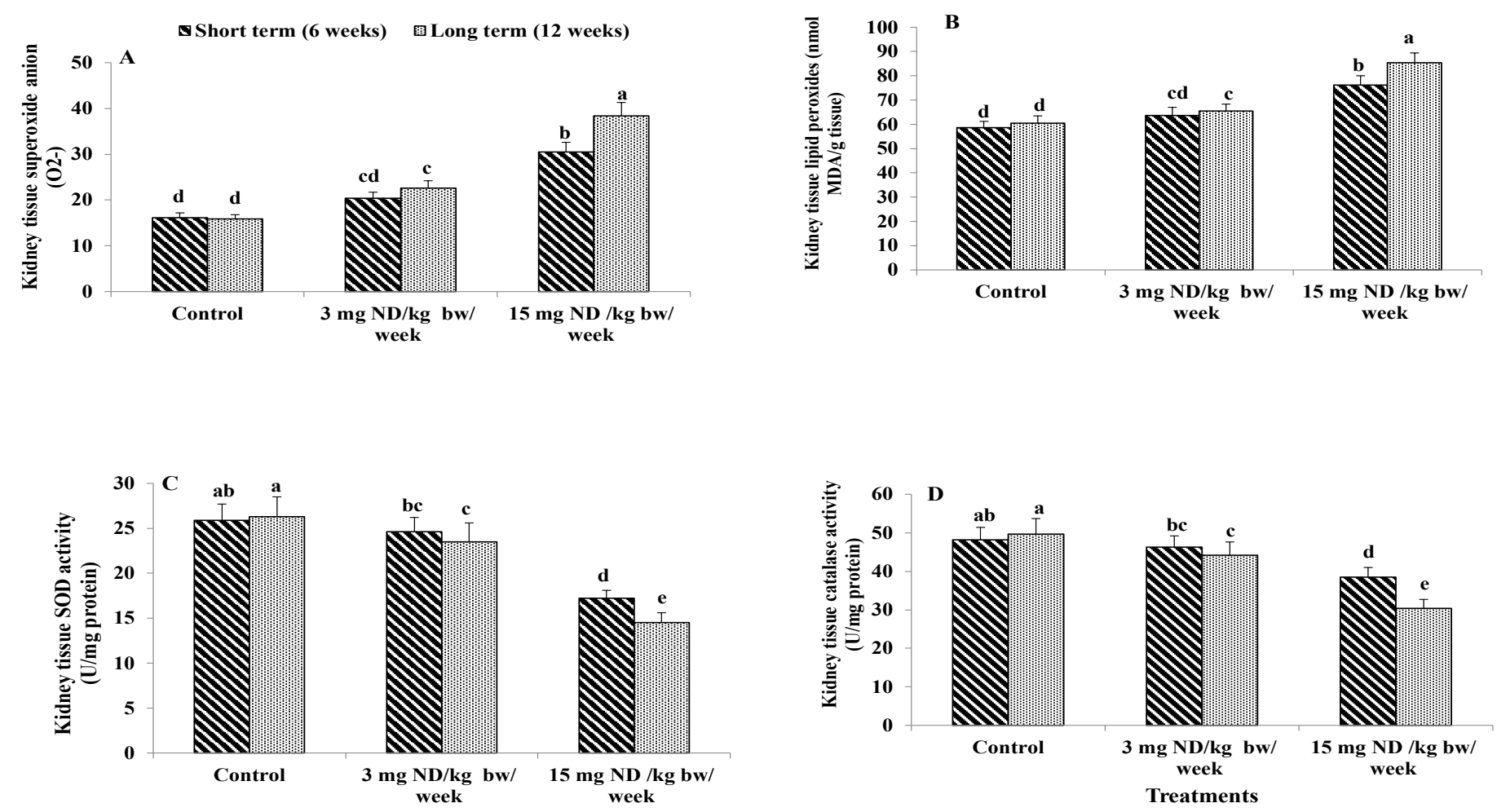

Figure 4. Effect of ND on oxidative stress biomarkers and antioxidant activities. Kidney tissue superoxide anion (A) kidney tissue lipid peroxides (B) Kidney tissue superoxide dismutase activity (C) and kidney tissue catalase activity (D) Different letters on columns indicate statistically.

NAG(N-acety- $\beta$-D glucosaminedase is a lysosome enzyme widely distributed in body tissue. It is released into serum from cells by exocytosis or from the breakdown of cells [38]. In this regard the high ND dose for either short or long term and the recommended ND dose for long term significantly elevated serum NAG activity. Determination of NAG may be noninvasive useful test for the early identification of patients who will subsequently develop renal disease [39]. The elevated serum NAG activity may be related to various cardiovascular risk factors, including atherosclerosis, elevated serum cholesterol and increased uric acid [40]. Li et al. [41] reported that increase in oxygen free radical leads to destruction of lysosomal membrane with subsequent release of NAG enzyme.

Aspartate aminotransferase (AST) and alanine aminotransferase (ALT) are the two of the most reliable markers of hepatocellular injury or necrosis [42]. Their levels can be elevated in a variety of hepatic disorders. The overdose of ND administration for either short or long term significantly elevated AST and ALT activities, cytosolic AST and cytosolic ALT as well as mitochondrial AST. These results are in the same line with the findings of Vierira et al. [43] and Mohammed et al. [9] who reported higher values of AST and ALT in the rats ingested with high ND dose and this behavior is repeated in low ND dose for long term with lower increments. Shahraki et al. [44] revealed that chronic administration of ND causes increased liver toxicity in male rats by altering the liver enzymes, lipid profile and blood parameters. In addition, administration of supraphysiological doses of ND alters glucose metabolism and lipid profile in albino rats [35].

Ingesting male rats with either low or high ND dose for both short and long term had insignificant effects on thyroid function $\left(\mathrm{T}_{3}, \mathrm{~T}_{4}\right)$ and TSH). However, $\mathrm{T}_{3}$ and $\mathrm{T}_{4}$ tended to increase, but TSH tended to decrease. These results are in agreement with the finding of Jepson et al. [45]. The slight increase of T3 and T4 level may be due to tyrosine content which is essential in the formation of thyroid hormones. However, the decrease in TSH level is due to the inverse feedback relationship between serum T4 and TSH applied across their normal ranges as well as in disease state as indicated by Ekins [46]. Thyroid gland is one of the non-classical target organs for androgen. The role of ND in thyroid gland structure is not yet fully understood [47]. It was reported that gonadal steroids affect thyroid gland not only in a direct manner through androgen receptors on thyroid follicular cell but also indirectly through the hypothalamic pituitary axis.

The current study revealed that injection male rats with high ND dose for short or long term induced significant elevation in the plasma corticosterone concentration. In this regard similar finding was obtained by Schlussman et al. [48] who reported that administration of ND significantly increased circulating level of corticosterone.

On the other hand, the plasma ACTH concentration was significantly attenuated by ingesting male rats with low ND dose for long term and high ND dose for either short or long term. These results are in agreement with that obtained by [49].

The corticosterone secretion from the adrenal glands is controlled by the stimulus of adrenocorticotrophic hormone (ACTH) from the pituitary gland. ACTH is secreted in response to corticotropin releasing hormone $(\mathrm{CRH})$ and vasopressin from the hypothalamus. Increase in cortisol exerts negative feedback control on both $\mathrm{CRH}$, vasopressin and consequently on ACTH, leading to ACTH inhibition [50].

Regarding the effect of nandrolone decanoate (ND) on the levels of oxidant and antioxidant system, the current study revealed that ingesting male rats with high ND dose for either short or long term as well as low ND dose for long term induced significant elevation 
in superoxide onion $\left(\mathrm{O}_{2}\right)$ and malondialdehyde (MDA), while it significantly attenuated superoxide dismutase (SOD) and catalase activity in kidney tissues of rats as compared to the untreated control rats.

Malondialdehyde is a metabolite of lipid peroxidation, which is produced due to the reaction of superoxide anion $\left(\mathrm{O}_{2}\right)$ and polyunsaturated fatty acids. It is one of the end products of lipid peroxidation [51]. Jevdevic et al. [8] pointed out that the highest concentration of ND induced the most prominent changes in $\mathrm{O}_{2}$ and $\mathrm{H}_{2} \mathrm{O}_{2}$ dynamics, In, addition many studies confirm the negative influence of ND on oxidative stress parameters [35,52].

Kidney and liver are usually linked to oxidative stress, which is characterized by a disruption of redox signaling. Reactive oxygen species (ROS) such as superoxide anion radical $\left(\mathrm{O}_{2}^{-}\right)$and hydrogen peroxide $\left(\mathrm{H}_{2} \mathrm{O}_{2}\right)$, can be formed by xanthine-oxidase, cytochrome P-450 or mitochondrial electron transport chain as a byproduct or directly by the NADPH oxidase (NOX) family of enzymes [53]. Intracellular ROS levels are maintained at adequate levels by antioxidant systems that react with these molecules producing less reactive compounds. Catalase is involved in $\mathrm{H}_{2} \mathrm{O}_{2}$ detoxification, producing $\mathrm{H}_{2} \mathrm{O}$ directly, while superoxide dismutase (SOD) catalyzes the conversion of superoxide to $\mathrm{H}_{2} \mathrm{O}_{2}$ [54].

The metabolism of high ND doses by cytochrome P-450 monooxygenases would have increased greatly the production of ROS resulting in a state of oxidative stress and upregulation of the activities of the antioxidant enzymes such as SOD and catalase [55].

\section{Conclusion}

The use of high ND dose for either short or long term as well as the repeated use of recommended ND dose for long term had deleterious effects evidenced by impairing kidney and liver functions, deteriorating thyroid, adrenal glands activities and disturbing oxidant/antioxidant balance.

\section{References}

1. Eldof AC, Thurelius AM, Garle M, Rame A, Sjoqvist F (2003) The anti- doping hotline. a means to capture; the abuse of doping agents in the Swedish Society and a new service function in clinical pharmacology. Eur J Clin Pharmacacol 59: 571-577. [Crossref]

2. Saha B, Bajadhyaksha GC, Ray Sk (2009) Beneficial effect of nandrolone decanoate in wasting associated with HIV. J Indian Med Assoc 107: 295-299. [Crossref]

3. Allouh MZ, Rosser BW (2010) Nandrolone decanoate Increases satellite number in the chicken pectoralis muscle. Histol Histopathol 25: 133-140. [Crossref]

4. Chawla B, Iqbal FM, Chawla MS (2009) Nandrolone decanoate for the treatment of erythropoietin refractory anemia: a case series. Compr Ther 35: 199-203. [Crossref]

5. Shahidi NT (2001) A review of the chemistry,biological action and clinical applications of AnabolicAndrogenic steroids. Clin Ther 23: 1355-1390. [Crossref]

6. Tamaki T, Shiraishi T, Takeda H, Matsumiya T, Roy RR, et al. (2003) Nandrolone decanoate enhances hypothalamic biogenic amines in rats. Med Sci Sports Exerc 35: 32-38. [Crossref]

7. Yesalis CE, Bahrke MS (1995) Anabolic androgenic steroids. Sport Med 19: 326-340.

8. Jevdevic M, Jovanovic M, Jeremie N, Cankovic M, Jeremic J, et al. (2015) Acute effects of namdrolone decanoate on oxidative stress in isolated heart. Arch Biol Sci Belgrade 67: 331-337.

9. Mohammed ARS, Al.Galad GM, AbdElgayd AA, Mwaheb MA, Elhanbuli HM (2017) Effect of nanrolone decanoate (anabolic steroid) on the liver and kidney of male albino rats and the role of antioxidant (antox - silymarin. as Adjuvant Therapy. J Drug Metab Toxicol 8: 1-11.

10. Do Carmo EC, Fernandes T, Koike D, Da Silva ND Jr, Mattos KC, et al. (2011) Anabolic steroid associated to physical training induces deleterious cardiac effects. Med Sci Sport Exerc 43: 1836-1848. [Crossref]
11. Su TP, Pagliaro M, Schmidt PJ, Pickar D, Wolkowitz O, et al. (1993) Neuropsychiatric effects of anabolic steroids in male normal volunteers. JAMA 269: 2760-2764. [Crossref]

12. Tahtamouni LH, Mustafa NH, Hassan IM, Ahmad IM, Yasin SR, et al. (2010) Nondrolone decanoate administration to male rats induces oxidative stress, seminiferous tubules abnormalities and Sperm DNA fragmentation. Jordan J Biol Sci 3: 165-174.

13. Andreato LV, Esteves JVD, Lmeida FN, Ribeiro TAD, Barrena AC, et al. (2013) Use of the anabolic steroid nandrolone decanoate associated to strength training in albino rats. Acta Scientiarum Biological Sciences Maringá 35: 283-291.

14. Henry RJ (1974) Clinical chemistry, Principles and Technics. ( $2^{\text {nd }}$ Edition) Harper and Row Publishers, New York, USA, pp: 267.

15. Searcy RL, Reardon JE, Foreman JA (1967) Enzymatic serum urea determination. Am J Med Technol 33: 15-20. [Crossref]

16. Haisman P, Muller BR (1977) Glosary of clinical chemistry terms. Butterworth, London, UK, pp: 126.

17. Luqmani Y, Temmim L, Memon A, Abdulaziz L, Parkar A, et al. (2001) Measurement of serum N-Acetyl- $\beta$-GlucosaminidaseActivity In Patients with breast cancer. Acta Oncol 38: 649-653. [Crossref]

18. Reitman S, Frankel S (1957) The colorimetric method for determination of serum glutamic oxaloacetie transaminase and serum glutamic pyruvic transaminase. $\mathrm{Am} \mathrm{J}$ Clin Pathol 28: 56-63. [Crossref]

19. Walker WHD (1977) Enzyme immunoassay for the quantitative determination of triiodothyronine (T3) in human serum. Clin Chem 23: 384.

20. Schuurs AH, Van Weemen BK (1977) Enzyme- Immune Assay. Clin Chim Acta 81 1-40. [Crossref]

21. Morimoto K, Inouye K (1997) Sensitive enzyme immune assay of human thyroid stimulating hormone (TSH) using biospecific $\mathrm{F}(\mathrm{ab}) 2$ fragments recognizing polymerized alkaline phosphatase and TSH. J Immunol Methods 205: 80-90. [Crossref]

22. Krame KM, Sothern RB (2001) Enzyme Immunoassays for the quantitative determination of corticosterone in serum or plasma. Chronobiol Int 18: 933-945.

23. Odell WD, Horton R, Pandian MR, Wong J (1989) The use of ACTH and cortisol Assay in the diagnosis of endocrine disorder. Nichols Institute Publication.

24. Hassoun EA, Stohs SJ (1996) Cadmium-induced production of superoxide anion and nitric oxide, DNA single strand breaks and lactate dehydrogenase leakage in J774A.1 cell cultures. Toxicology 112: 219-226. [Crossref]

25. Babior BM, Kipnes RS, Curnutte JT (1973) Biological defense mechanisms, the production by leukocytes of superoxide potential bactericidal agent. J Immunol 52: 741-744. [Crossref]

26. Placer ZA, Cushman LL, Johnson BC (1996) Estimation of lipid peroxidation (Malondialdehyde) in biochemical systems. Anal Biochem 16: 359-365. [Crossref]

27. Chromy V, Fischer J (1977) Photomtric determination of total protein in lipemic sera. Clin Chem 23: 754-756. [Crossref]

28. Marklund SL (1985) Pyrogallol autooxidation. Handbook of Methods for Oxygen Radical Research. Boca Raton Fl: Crc Press: 243-247.

29. Clairborne A (1985) Catalase Activity. Handbook of Methods for Oxygen Radical Research. Boca Ration Fl: Cre Press: 283-284.

30. Yeung D, Oliver IT (1967) Gluconeogenesis from amino acids in neonatal rat liver Biochem J 103: 744-750. [Crossref]

31. Hogeboom GH (1955) Methods in enzymology. Pub Academic Press, New York, London, UK, pp: 16.

32. Bosron WF, Veitch RL, Lumeng L, Li TK (1978) Subcellular localization and identification of pyridoxal 5- phosphate binding protein in rat liver. $J$ Biol Chem 253 : 1488-1492. [Crossref]

33. Bhasin S, Woodhouse L, Casaburi R, Singh AB, Bhasin D, et al. (2001) Testosterone dose response relationship in healthy young men. Am J Physiol Endocrinol Metab 281: E1172-E1181. [Crossref]

34. Casavant MJ, Blake K, Griffith J, Yates A, Copley LM (2007) Consequences of use of anabolic steroids. Pediatr Clin North Am 54: 677-690. [Crossref]

35. Frankenfeld SP, de Oliveira LP, Ignacio DL, Coelho RG, Mattos MN, et al. (2014) Nandrolone decanoate inhibits gluconeogenesis and decreases fasting glucose in albino male rats. $J$ Endocrinol 220: 143-153. [Crossref] 
36. Kang DH, Nakagawa T (2005) Uric acid and chronic renal disease: Possible implication of hyperuricemia on progression of renal disease. Semin Nephrol 25: 43-49. [Crossref]

37. Sato R, Soeta S, Syuto B, Yamagishi N, Sato J, et al. (2002) Urinary excretion of $\mathrm{N}$-acetyl $-\beta \mathrm{D}$-glvcosaminidase and its isoenzymes in cats with urinary disease. $J V e$ Med Sci 64: 367-371

38. Welman E, Selwyn AP, Peters TJ, Colbeck JF, Fox KM (1987) Plasma lysosomal enzyme activity in acute myocardial infarction. Cardiovasc Res 12: 99-105. [Crossref]

39. Bazzi C, Petrini C, Rizza V, Arrigo G, Napodano P, et al. (2002) Urinary N-acetyl - $\beta$ glucosaminidase excretion is a marke of tubular dysfunction and predictor of outcome in primary glomerulonephritis. Nephrol Dial Transplant 17: 1890-1896. [Crossref]

40. Hashimoto R, Adachi H, Nishida H, Tsuruta M, Nomura G (1995) Glucosaminidase activity in predicting the development of hypertension. Hypertension 25: 1311-1314.

41. Li WG, Zhang XY, Wu UJ, Tian X (2001) Anti-inflammatory effect and mechanism of proanthocyanidins from grape seeds. Acta Pharmacol Sin 22: 1117-1120. [Crossref]

42. Giboney PT (2005) Mildly elevated liver transaminase levels in the asymptomatic patient. Amer Fam Physician 71: 1105-1110. [Crossref]

43. Vieira RP, Franca RF, Damaceno-Rodrigues NR, Dolhnikoff M, Caldini EG (2008) Dose dependent heptic response of subchronic administration of nandrolone decanoate. Med Sci Sport Exer 40: 842-847. [Crossref]

44. Shahraki MR, Mirshekari H, Shahraki AR (2016) Chronic high doses of nandrolone decanoate on blood cell, lipoprotein profile, and liver enzymes in male rat. Zehedan $J$ Res Med Sci 18: 1-4.

45. Jepson MM, Bates PC, Millward DF (1988) The role of insulin and thyroid hormones in the regulation of muscle growth and protein turnover in response to dietary protein in rat. BrJ Nutr 59: 397-415. [Crossref]

46. Ekins R (1990) Measurement of free hormones in blood. Endocr Rev 11: 5-46 [Crossref]
47. Abdallah MA (2013) Effect of bilateral orchidectomy on thyroid gland structure of adult albino rats and the role of nandrolone decanoate administration. J Amer Sci 9: 879-888.

48. Schlussman SD, Zhou Y, Johansson P, Kiuru A, Ho A, et al. (2000) Effects of the androgenic anabolic steroid, nandrolone decanoate on adrenocorticotropin hormone, corticosterone and proopiomelanortin, corticotropin releasing factor (CRF) and CRF receptori mRNA levels in the hypothalamus, pituitary and amygdala of the rat. Neuro science Letters 284: 190-194. [Crossref]

49. Alsio J, Birgner C, Bjokblon L, Isaksson P, Bergstrom L, et al. (2009) Impact of nandrolone decanoate on gene expression in endocrine systems related to the adverse effects of anabolic androgenic steroids. Basic Clin Pharmacol Toxicol 105: 307-314 [Crossref]

50. Morris DG, Grossman AB (2002) Neuroendocrinology hypothalamus and pituitary cashing's syndrome. Text. Book Chapter: 7.

51. Karajibani M, Montazerifar F, Feizabad AK (2017) Study of oxidants and antioxidans in addicts. Int J High Risk Behav Addict 6: 1-9.

52. Sun M, Shen W, Zhong M, Wu P, Chen H, et al. (2013) Nandrolone attenuates aortic adaptation to exercise in rats. Cardiovasc Res 97: 686-695. [Crossref]

53. Aguirre J, Lambeth JD (2010) Nox enzymes from fungus to fly to fish and what they tell us about Nox function in mammals. Free Radic Biolo Med 49: 1342-1353. [Crossref]

54. Jones DP (2008) Radical-free biology of oxidative stress. Am J Physiol Cell Physiol 295: 849-868.

55. Pey A, Saborido A, Blazquer I, Delgado J, Megias A (2003) Effect of prolonged stanozolol treatment on antioxidant enzyme activities, oxidative stress markers and heat shock protein HSP 72 levels in rat liver. J Steroid Biochem Mol Biol 87: 269-277. [Crossref]

Copyright: (C2019 Salem NA. This is an open-access article distributed under the terms of the Creative Commons Attribution License, which permits unrestricted use, distribution, and reproduction in any medium, provided the original author and source are credited. 